\title{
A167 INTERLEUKIN10-PRODUCING CD4 T CELLS AMELIORATE MURINE LUPUS IN NZB/W F1 MICE
}

R Undeutsch, A Papendieck, J Y Humrich, G Riemekasten Charité Berlin/German Arthritis Research Centre Berlin, Charitéplatz ${ }^{1}$, Berlin

\subsection{6/ard.2010.129668d}

Systemic lupus erythematosus (SLE) is a severe systemic chronic autoimmune disease and NZB/W F1 mice are commonly used to study this disease. The role of interleukin 10 (IL10) in SLE is controversial and needs to be clarified, especially with regard to the different cell types which can produce IL10. Here the authors show that IL10 produced by CD4 T cells plays a beneficial role in murine lupus of NZB/W F1 mice, even in full-blown disease in old NZB/W F1 mice. The authors (1) detected SmD1(83-119)-specific CD4 IL10 T cells after a previously published SmD1(83-119) high-dose tolerisation protocoll and were able to increase the number of these cells by an additional booster immunisation with SmD1(83-119); (2) showed that IL10 has a suppressive effect on anti-dsDNA autoantibody production at least in vitro; (3) achieved a temporary beneficial effect on the course of proteinuria and autoantibody development by transfer of CD4 T cells containing up to $0.04 \% \mathrm{SmD} 1(83-119)$-specific CD4 IL10 T cells from SmD1(83-119) high-dose tolerised NZB/W F1 mice into untreated NZB/W F1 mice; and (4) were able to treat full-blown lupus disease in old female NZB/W F1 mice with in vitro generated polyclonal CD4 IL-10 IL4 T cells, improving significantly the survival of these mice in contrast to a control transfer of in vitro generated polyclonal CD4 IFN $\gamma+\mathrm{T}$ cells or PBS-treated control mice. The authors conclude that IL10 produced by CD4 T cells has a beneficial effect in murine lupus, even in full-blown disease in old severely ill lupus-prone NZB/W F1 mice.

\section{REFERENCE}

1. Riemekasten G, Langnickel D, Enghard P, et al. Intravenous injection of a D1 protein of the Smith proteins postpones murine lupus and induces type 1 regulatory T cells. J Immunol 2004;173:5835-42. 